nificancia" empírica; el cuarto interrumpe la discusión anterior para estudiar la doctrina de la interpretación parcial de términos teóricos y la teoría de doble nivel del lenguaje científico; el quinto vuelve a tomar la discusión del principio del empirismo, basándose en una exposición y discusión crítica del criterio de Carnap de la "significan. cia" empírica para términos teóricos; el sexto se ocupa con la demostración y discusión del famoso y sorprendente teorema de $W$. Craig, que propone una sustitución funcional de los términos teóricos; finalmente, el séptimo se dedica al estudio de la aportación "tal vez más interesante e importante" para interpretar los conceptos teóricos: la proposición Ramsey de una teoría, entendida como sustitución de la teoría original mediante eliminación de los conceptos teóricos problemáticos.

Séale lícito a un casi laico o neófito -en la materia ofrecer con lo anterior un sumario del contenido de tan importante obra, resumen que espero cumpla la misión de presentarla y atraer a su lectura. En cuanto al estilo o forma de expresión, yo la encuentro fácil y suavemente legible; y puede afirmarse que, cuando un extranjero es capaz de leer así un libro en alemán, quiere decir que en realidad se trata de algo escrito con las mejores cualidades de expresión. Al respecto dice Feigl en una reseña sobre el primer tomo: "El estilo del autor no tiene nada de la tenacidad teutónica, y ciertamente nada de la ampulosidad u oscuridad que se podría esperar (no injustificadamente) de una obra alemana de ese tamaño colosal." (The Journal of Philosophy, vol. LXVII, núm. 8, abril de 1970, p. 249).

Para una valoración crítica de la obra, por desgracia tampoco estoy capacitado, especialmente en lo que se refiere al contenido, es decir, al valor de las aportaciones, a la verosimilitud de las hipótesis, al acierto de los métodos, etc. Por ello, y a fin de que el lector de esta nota no ignore lo esencial al respecto, me permito transcribir dos breves párrafos de las reseñas ya citadas. Feigl dice: "En la presente obra Stegmüller procede no sólo como un experto relator e intérprete, sino que también proporciona un buen número de importantes ideas nuevas, parcialmente basadas en penetrantes análisis críticos de contribuciones previas a la lógica de la explanación científica y a los problemas relacionados de la Begründung (justificación)." (P. 259.) El autor de la otra reseña, Joseph J. Kockelmans, valora así los méritos del primer tomo, lo que sin duda puede aplicarse también al segun. do: "En la preparación del libro el autor ha examinado una enorme cantidad de literatura sobre el tema. La bibliografía contiene unos 250 números, la mayor parte de los cuales ha sido estudiada muy seriamente en el contenido del libro. La descripción de los puntos de vista de otros autores es siempre objetiva y clara; donde Stegmüller desarrolla ulteriormente estas ideas, lo ejecuta sobre la base de una evidencia apropiada; donde sugiere cambios, indica claramente sus argumentos para tales cambios; y cuando critica un punto de vista, es siempre una crítica convincente" (p. 131).

BernabÉ Navarrọ

Las mocedades de Ortega y Gasset, por Fernando Salmerón, Seminario de Filosofía Contemporánea. Colegio de Filosofía. Facultad de Filosofía y Letras. Universidad Nacional Autónoma de México, $2^{\text {a }}$ ed., 1971.

Doce años después de su primera edición publicada por El Colegio de México, aparece ahora, editado por la Universidad, el libró de Fernando Salmerón Las mocedades de Ortega y Gasset. El hecho encomiable de la reedición de 
estudios sobresalientes realizados en décadas pasadas, obliga a una breve nota a propósito de esta obra en particular.

Cabe recordar que el voluminoso trabajo del autor, fue dirigido por el Doctor José Gaos y presentado como tesis para la obtención de un grado académico. La investigación, que excedió con holgura estas exigencias fue comentada con cierta amplitud tanto por los estudiosos de las materias filósoficas e históricas como por quienes siguen a tientas el desenvolvimiento de estos temas. En resumen, los primeros reconocieron que el estudio de Salmerón se diferenciaba singularmente de otros análisis que, aunque excelentes, no proyectaban una investigación general de los diferentes tramos por los que merodeó el filósofo español. Con el examen detenido, exhaustivo quizá, de la primera etapa del pensamiento de Ortega que abarca apenas doce años, a saber, entre 1902 y 1913 se daba el primer paso sistemático a todo estudio posterior sobre el contenido de la obra orteguiana. El mérito de esto, escribió el doctor Udo Rusker en una publicación suiza, corresponde a Fernando Salmerón quien ha procedido de tal manera que "trata de expli. car a Ortega por sí mismo", y quien en. tiende esta filosofía como el desarrollo histórico de un espíritu filosófico, como una reacción contra el tiempo y contra la circunstancia que sólo puede ser comprendida en el orden biográfico.

La clasificación de las primeras publicaciones con las que abrumó Ortega a sus maestros, discípulos y lectores hubo de ser ardua, dado que los escritos de juventud se refieren a innumera. bles temas. Sin embargo, el autor centró su examen en: El problema de España; El tema de la cultura; La ciencia, el método y el problema de la verdad; El arte, la estética y la crítica; La idea de la vida; La idea de la historia; El hombre y la sociedad; Dios, la religión y la fe; El ser. La realidad. Las cosas; atendiendo el último apartado a un apéndice en el que se incluye una pano- rámica general de la vida económica, social y cultural de ese país desde prin. cipios del siglo Xix hasta el momento en que termina el periodo en que transcurren las "Mocedades". El despliegue muy vasto de los intereses primeros de Ortega quedó encasillado en estos apartados que facilitan la explicación ordenada de los incontables fragmentos en que quedó dispersa y mezclada la temática política con las ocurrencias filosóficas y las obsesiones literarias.

El análisis incurre dentro del cuerpo de influencias que perduraron en el joven Ortega: los krausistas, Miguel de Unamuno, Ángel Ganivet, Joaquín Costa, Taine, Renan, Goethe, Nietzsche, Cohen, Natorp, Simmel, Freud y Husserl. Es preciso apuntar que los temas que acapararon la atención de Ortega y que dieron origen a incontables artículos, polémicas, ensayos y conferencias reflejan un señalado interés por la "europeización" de España. Europa es entonces el escenario de una afiebrada actividad intelectual que - a consecuencia de los descubrimientos científicos de principios de siglo replantea todos los principios sobre los cuales se fundaban los conocimientos científicos y las diversas doctrinas filosóficas. El espectáculo de la inestabilidad política y económica en los años que anteceden a la primera Guerra Mundial, acentúa la confusión que nace de las nuevas teorías científicas y filosó. ficas. La conciencia más o menos clara de las profundas transformaciones que se producen en el mundo se traduce, en todos los dominios del pensamiento y del arte, en una voluntad de renovación: Este deseo de transformación obsedió el interés de Ortega en estos años en los que publicó numerosos y notables artículos de comentario de la vida pública española y crítica literaria, acogidos, y comentados en los sectores intelectuales por la extensa erudición qque denotaban, por su visión clara y personal de los problemas de España y por la singularidad de su prosa. La marcada insistencia en sus ensayos acerca de que 
los españoles debían inclinarse por el aprendizaje riguroso de las disciplinas científicas responde a la preocupación de propiciar la participación española en el cambio radical que confronta el pensamiento europeo. La psicología y la sociología que estudia Ortega reconsideran también los fundamentos de sus métodos. En psicología se supera la introspección y la psicofísica, la teoría de la forma, la psicología experimental, etc., se ven eclipsados por el psicoanálisis de Freud, cuyos trabajos influyen en los medios literarios y artísticos. La sociología se constituye como ciencia autónoma de las sociedades y ejerce una influencia decisiva sobre las otras ciencias humanas. La historia utiliza los trabajos de arqueólogos, economistas y sociólogos para ampliar su horizonte y mejorar su conocimiento de civilizaciones casi ignoradas. A esto contribuye Ortega vivamente al sostener, contra una tradición ingenua, una nueva visión que enriquece el conocimiento sobre el arte mediterráneo prehistórico y sobre algunas de las obras más memorables del arte en general, que por entonces detienen la atención de Ortega.

Las reacciones provocadas por estos años de incertidumbre, que se manifiestan por la aparición de disturbios sociales y reivindicaciones políticas, tienen como parangón en el orden literario y artístico una fermentación general de las ideas que somete a crítica a todo tipo de convenciones. En su polémica con Valera, rechaza su "crítica niveladora" que destruye la jerarquía de los valores intelectuales. Para Ortega la primera tarea del crítico consiste en reducir lo excesivo, elevando las verdades no reconocidas por el vulgo. La segunda empieza con un ennoblecimiento, siquiera provisional, de lo sometido a la crisis. Sólo de esta manera es la crítica un verdadero género literario o científico. Si bien la opinión anterior filosóficamente no nos asc:gura nada, revela que aun en Ortega se produce la reacción de ruptura del hombre que está en camino de apren. der a pensar en sí mismo como un incidente pasajero y un estadio provisional de un mundo en transformación.

Sin duda, resultaría impertinente resumir todos y cada uno de los convenien. tes hallazgos que logra desentrañar el autor a lo largo de su trabajo. Los temas que rozamos aparecen esclarecidos con llaneza fusionados a otros no menos im. portantes, en los que Salmerón despeja las incógnitas de este periodo de la vida de Ortega. Puede considerarse cumplida la tarea del autor en la medida en que proporciona el hilo conductor de la primera evolución de Ortega y en que posibilita la comprensión segura del transcurso de su madurez.

\section{JorGe Graue.}

\section{Bibliografía Filosófica Mexicana 1969. Seguida le la bibliografía del doctor :osé Gaos, Universi- dad Nacional Autónoma de Méxi- co, Instituto de Investigaciones Bibliográficas-Instituto de Inves- tigaciones Filosóficas, año II, n⿳⺈ 2, 1971.}

El trabajo realizado por quienes estuvieron al cuidado de la compilación de la bibliografía cumple su objetivo más próximo al suministrar el medio para obtener lo más pronto y lo más completamente posible, la información sobre el repertorio filosófico publicado en México a lo largo de un año. Cabe además arguiir, en su favor, el hecho de que el trabajo efectuado se ajusta todavía a las necesidades de nuestro medio.

Reconocido uno de los aspectos meritorios de quienes efectuaron con paciencia y acuciosidad esta labor, se nos ocurre una observación que habrá que precisar. Lo que podría objetarse se relaciona con el criterio riguroso de una bibliografía, definida ésta como aquella rama de la bibliografía que hace la des- 